\title{
Tritium-Labeled Compounds XII. Note on the Synthesis of D-Glucose-2-t and D-Mannose-2-t
}

\author{
Horace S. Isbell,* Harriet L. Frush, C. W. R. Wade, and A. J. Fatiadi \\ Institute for Materials Research, National Bureau of Standards, Washington, D.C. 20234
}

(July 9, 1968)

\begin{abstract}
D-Glucose-2- $t$ and D-mannose-2- $t$ have been synthesized from sodium 2-keto-D-gluconate (sodium D-arabino-hexulosonate). Reduction of the salt with lithium borohydride- $t$ produced the epimeric, 2-labeled aldonic acids in almost equal proportions. The acids, separated by carrier techniques, were lactonized, and the lactones were reduced with sodium amalgam to the corresponding sugars. The specificity of the labeling was established by converting each sugar into D-arabino-hexulose phenylosazone and determining that the osazone was substantially tritium-free.
\end{abstract}

Key Words: D-Gluconic-2- $t$ acid, synthesis of;

D-Glucose-2-t, synthesis and radioanalysis of; D-Mannonic-2-t acid, synthesis of;

D-Mannose-2-t, synthesis and analysis of;

Sodium 2-keto-D-gluconate, reduction with lithium borohydridet; sugars, tritium-

labeled; tritium-labeled compounds,

D-mannose-2- $t$ and D-glucose-2- $t$.

\section{Introduction}

In connection with a study of the behavior of sugars in alkaline solution [1], ${ }^{1}$ several sugars labeled with tritium on C-2 were needed. Syntheses of D-glucose-2-t and D-mannose-2-t began with sodium 2-keto-D-gluconate (sodium D-arabino-hexulosonate); reduction of the ketonic carbonyl group with lithium borohydride- $t$ provided a mixture of 2-labeled D-gluconic and Dmannonic acid. The acids were separated and lactonized, and the lactones were reduced with sodium amalgam by the procedures previously developed for preparing the corresponding ${ }^{14} \mathrm{C}$-labeled sugars ${ }^{2}$ [2].

Because the reduction of sodium 2-keto-D-gluconate with lithium borohydride- $t$ was conducted in alkaline solution, it seemed possible that a $\mathrm{C}-2-\mathrm{C}-3$ enolization might have occurred and resulted in products having some tritium on $\mathrm{C}-3$ as well as on $\mathrm{C}-2$. However, the absence of tritium at positions other than C-2 was established by converting the labeled D-glucose and D-mannose into their common phenylosazone (D-arabino-hexulose phenylosazone). After three recrystallizations, the phenylosazone from each sugar was found to be essentially free of tritium, indicating

\footnotetext{
*Present address: Chemistry Department, American University, Washington, D.C. 20016. ' Figures in brackets indicate the references at the end of this paper.

${ }^{2}$ A similar reduction of sodium 2-keto-D-galactonate (sodium D-/vxo-hexulosonate) followed by procedures analogous to those described in ref. 3, yielded D-galactose-2- $t$ and D-talose-2-t.
}

the absence of labeling on $\mathrm{C}-3, \mathrm{C}-4, \mathrm{C}-5$, and $\mathrm{C}-6$. Absence of labeling on $\mathrm{C}-1$ of the sugars may be assumed because the introduction of hydrogen on $\mathrm{C}-1$ (by reduction of the lactone with sodium amalgam) was carried out as a separate step after the labeling had been completed. Hence the D-glucose and D-mannose must be labeled exclusively on $\mathrm{C}-2$.

\section{Experimental Procedures}

\subsection{Reduction of Sodium 2-keto-D-Gluconate With Lithium Borohydride-t}

Sodium 2-keto-D-gluconate monohydrate was prepared from calcium 2-keto-D-gluconate monohydrate ${ }^{3}$ [4] by treating the latter with an equivalent proportion of sodium oxalate, removing the calcium oxalate precipitated, and crystallizing the sodium 2-keto-Dgluconate monohydrate from the resulting solution.

A magnetic stirring-bar, $936 \mathrm{mg}$ ( 4 mmoles) of sodium 2-keto-D-gluconate monohydrate, $10 \mathrm{mg}$ of sodium carbonate, and $4 \mathrm{ml}$ of water were placed in a $100-\mathrm{ml}$, round-bottomed flask having a small side-arm provided with a rubber cap suitable for perforation by a hypodermic needle. The solution was frozen, and the flask was evacuated on a vacuum manifold [5]. The flask was then closed off, the frozen solution was melted,

\footnotetext{
${ }^{3}$ The authors thank Peter Regna of Chas. Pfizer \& Co., Inc., for the calcium 2-keto-Dgluconate used in this work.
} 
and stirring was begun. With the flask in an ice-bath, 2 -ml of a $0.5-M$ solution of lithium borohydride- $t$ in dry tetrahydrofuran $(40 \mathrm{mCi})$ was added by injection with a hypodermic needle through the capped sidearm. Stirring was continued for $2 \mathrm{hr}$ at $0{ }^{\circ} \mathrm{C}$, and the mixture was kept overnight at room temperature.

Aqueous acetic acid (1 $\mathrm{ml}$ of $5 \%$ ) was injected to decompose any unreacted lithium borohydride- $t$, and, after the solution had been refrozen, hydrogen- $t$ was collected in the manifold. The solvent was removed by freeze-drying (and was ultimately discarded in the manner approved for radioactive waste). The residue, dissolved in water, was passed through a small column of a strongly acidic cation-exchange resin $(10 \mathrm{ml})$, and the effluent was evaporated to dryness under vacuum. Boric acid was removed from the residue as methyl borate by several successive additions of methanol, each followed by evaporation under vacuum.

An aqueous solution of the labeled products (volume $25 \mathrm{ml}$ ) was found to contain $18.9 \mathrm{mCi}$ of radioactivity. The proportions of labeled D-gluconic and D-mannonic acid in the solution were determined by isotope dilution: a $100-\mu l$ aliquot was added to an aqueous solution containing $200 \mathrm{mg}$ of barium D-gluconate trihydrate. This solution was then neutralized with aqueous barium hydroxide, and concentrated. The carrier crop was crystallized from aqueous methanol-isopropyl alcohol, and recrystallized three times. A second $100-\mu$ aliquot was added to a solution of $200 \mathrm{mg}$ of D-mannono-1,4-lactone. This solution was treated with aqueous sodium hydroxide sufficient to produce a faint, permanent, pink color with phenolphthalein indicator and was then passed through a small column $(5 \mathrm{ml})$ of the cation-exchange resin; the effluent was evaporated to dryness under vacuum. The residue was dissolved in methanol, and the solution was heated at $70{ }^{\circ} \mathrm{C}$ for $1 \mathrm{hr}$ to effect lactonization. The solvent was evaporated, and the lactone was crystallized and twice recrystallized, from methanol-isopropyl alcohol. Radioactivity found from the assay of the carriers: D-gluconic-2- $t$ acid, $8.83 \mathrm{mCi}(46.7 \%$ of the labeled products); D-mannonic-2-t acid, $9.91 \mathrm{mCi}$ (52.4\%).

\subsection{Preparation of Barium D-Gluconate-2-t and D-Glucose-2-t}

The solution containing D-gluconic-2- $t$ and D-mannonic-2- $t$ acid was neutralized with barium hydroxide and concentrated. Crystallization of barium D-gluconate was initiated by the addition of ethanol to incipient turbidity, and the resulting crystals were separated and recrystallized. The combined mother liquor was depleted of D-gluconate-2-t ions by five additional crystallizations with nonradioactive barium D-gluconate used as carrier (total, $2.5 \mathrm{~g}$ ). Each carrier crop was recrystallized, and the mother liquors were combined for the next carrier crystallization. The first crystals and the carrier crops were selectively combined and recrystallized to give the following quantities of barium D-gluconate-2- $t$ monohydrate: $1.155 \mathrm{~g}$ $(5,700 \mu \mathrm{Ci}) ; 1.460 \mathrm{~g}(1,290 \mu \mathrm{Ci})$; and $1.100 \mathrm{~g}(320 \mu \mathrm{Ci})$; total yield, 83 percent of the D-gluconic- $2-t$ acid found by analysis.

The two main crops of barium D-gluconate-2- $t$ trihydrate $(6,990 \mu \mathrm{Ci})$ were converted into D-glucono-1,5lactone-2-t, and this was reduced with sodium amalgam in the presence of sodium hydrogen oxalate by the procedure previously described for the preparation of D-glucose- $2-{ }^{14} C$ [2]. The yield of $\alpha$-D-glucose-2- $t(5,430$ $\mu \mathrm{Ci})$ was approximately 78 percent of the barium D-gluconate-2-t, or 65 percent of the quantity initially found by analysis.

\subsection{Preparation of D-Mannono-1,4-lactone-2-t and D-Mannose-2- +}

Nonradioactive calcium D-mannonate dihydrate (1 g) was added to the mother liquor that had been depleted of its barium D-gluconate-2-t. An aqueous solution of the mixture was passed through $25 \mathrm{ml}$ of the cation-exchange resin, and the effluent was evaporated under vacuum. The residue was digested for $1 \mathrm{hr}$ in methanol at $70{ }^{\circ} \mathrm{C}$, and the solution was then cooled, nucleated with D-mannono-1,4-lactone, and kept in a desiccator for several days. Crystalline D-mannono-1,4-lactone-2- $t$ deposited and was separated. Residual, labeled lactone was isolated from the mother liquor in carrier crops by several co-crystallizations with nonradioactive D-mannono-1,4-lactone; yield, $7.48 \mathrm{mCi}$, or approximately 75 percent of the quantity found by analysis. The crops were combined, recrystallized, and then reduced in 1-mmole portions by the method described for the preparation of $\alpha$-Dmannose- $2{ }^{14} C$ [2]. The yield of $\alpha$-D-mannose-2- $t$ was approximately 65 percent of the labeled lactone employed, or 49 percent of the D-mannonic-2-t acid found by analysis.

\subsection{Preparation of D-arabino-Hexulose Phenylosazone from $D$-Glucose-2-t}

A mixture containing $100 \mathrm{mg}$ of D-glucose-2-t (11.53 $\mu \mathrm{Ci}), 200 \mathrm{mg}$ of phenylhydrazine hydrochloride, and $300 \mathrm{mg}$ of anhydrous sodium acetate was dissolved in $4 \mathrm{ml}$ of water in a $15-\mathrm{ml}$ centrifuge tube, and the solution was kept in a boiling-water bath for $20 \mathrm{~min}$. The resulting suspension of yellow crystals was diluted with $4 \mathrm{ml}$ of water, kept in ice-water for $30 \mathrm{~min}$, and then centrifuged; the separated crystals were washed twice with $3-\mathrm{ml}$ portions of water. To recrystallize the product, the moist crystals were dissolved in $3 \mathrm{ml}$ of $2: 1 \quad(v / v)$ methyl Cellosolve-tetrahydrofuran, and water was added drop-wise, with stirring, to give a total volume of about $12 \mathrm{ml}$. The resulting, fluffy precipitate was centrifuged and washed as before. The recrystallization process was twice repeated, and the separated crystals were dried in a vacuum desiccator.

For analysis, $3.5 \mathrm{mg}$ of the phenylosazone, in a standard liquid-scintillation bottle, was dissolved in one drop of tetrahydrofuran, and $10 \mathrm{ml}$ of a scintillation mixture containing $p$-dioxane was added; the solution was assayed in a liquid-scintillation spectrometer. The radioactivity of the phenylosazone was $1.84 \mathrm{~d} / \mathrm{s}$ per 
milligram; the radioactivity of the equivalent quantity of the parent D-glucose-2-t $(0.503 \mathrm{mg})$ had been 2145 $\mathrm{d} / \mathrm{s}$. Hence retention of radioactivity by the D-arabinohexulose phenylosazone was less than 0.1 percent, and the compound was substantially tritium-free.

\subsection{Preparation of D-arabino-Hexulose Phenylosazone From D-Mannose-2-t}

A solution of $200 \mathrm{mg}$ of phenylhydrazine hydrochloride and $300 \mathrm{mg}$ of sodium acetate in $10 \mathrm{ml}$ of water was treated with sufficient acetic acid to bring the $\mathrm{pH}$ to 4.6 . To this solution was added $100 \mathrm{mg}$ of D-mannose-2-t (containing $8.16 \mu \mathrm{Ci}$ of radioactivity), and the solution was heated in a boiling-water bath for $1 \mathrm{hr}$. A colorless precipitate of D-mannose phenylhydrazone formed at first and redissolved, and the yellow phenylosazone then precipitated. The sus- pension was diluted with $5 \mathrm{ml}$ of water, cooled in icewater, and centrifuged. The precipitate was washed, and recrystallized three times, as described for the phenylosazone of D-glucose-2-t. The radioactivity, measured with $5.2 \mathrm{mg}$ of the dried phenylosazone, was scarcely greater than that of the background.

\section{References}

[1] Isbell, H. S., and Frush, H. L., Abstracts Papers, Am. Chem. Soc. Meeting, 155, C25 (1968).

[2] Isbell, H. S., Frush, H. L., and Schaffer, R., J. Res. NBS 54, 201 (1955)RP2581.

[3] Isbell, H. S., Frush, H. L., and Holt, N. B., J. Res. NBS 53, 217 (1954)RP2536.

[4] Regna, P. P., and Caldwell, B. P., J. Am. Chem. Soc. 66, 243 (1944).

[5] Isbell, H. S., and Moyer, J. D., J. Res. NBS 63A (Phys. and Chem.), No. 2, 177 (1959).

(Paper 73A1-537) 